\title{
Formação de Preços como Processo Complexo
}

\author{
ELEUtÉrio F. S. Prado*
}

\begin{abstract}
RESUMO
O artigo parte da dificuldade do economista "moderno" em compreender o modo como Marx e os economistas clássicos pensavam a formação de preços. Com base na distinção entre microeconomia reducionista e microeconomia sistêmica, compara esse modo com aquele da teoria neoclássica. Para tanto, examina em seqüência três tipos de representações da formação de preços: o mercado como coerência, o mercado como equilibrismo e o mercado como processo. Mostra que o modo "antigo" de pensar o funcionamento do mercado pode ser reconstruído com base na teoria econômica computável. O mercado, enquanto mera aparência do modo de produção capitalista, é então teoricamente representado como algoritmo, ou seja, como mercatômato.
\end{abstract}

Palavras-CHAVE

formação de preços, microeconomia sistêmica, teoria econômica neoclássica, Economia Política Clássica, mercatômato.

\begin{abstract}
The paper arise from the troubles of "moderns" economists for understanding how Marx and the classical economists thought about the formation of prices. On the base of the distinction between reductionist microeconomics and systemic microeconomics, it compares that mode with the mode of thinking of neoclassical theory. For that, investigate three types of prices formation representations: the market as coherence, the market as equilibrium and the market as process. It shows that the "old" mode of thinking the working of the market can be reconstructed on the base of computable economics. Then the market - while appearance of capitalist mode of production - is theoretically described as an algorithm, that is, as markomata.
\end{abstract}

KEY WORDS

formation of prices, systemic microeconomics, neoclassical economic theory, Classical Political Economy, markomata.

JEL Classification

B4I, D59

* Professor da USP. Endereço para contato: FEA-USP: Av. Prof. Luciano Gualberto, 908 - Cid. Universitária - São Paulo - SP - CEP 05508-0I0. E-mail: eleuter@usp.br.

(Recebido em junho de 2006. Aceito para publicação em março de 2007). 


\section{INTRODUÇÃO}

As considerações que se seguem de Karl Marx em $O$ Capital dificilmente podem ser compreendidas de modo imediato por economistas formados nos moldes teóricos do século XX:

"Nada é mais fácil do que compreender as desigualdades entre procura e oferta e o desvio conseqüente dos preços de mercado em relação aos valores de mercado. A verdadeira dificuldade consiste em determinar o que se deve entender por coincidência entre procura e oferta. [...] Procura e oferta de fato jamais coincidem, ou, se alguma vez coincidirem, é por mera causalidade; portanto do ponto de vista científico, deve-se admitir que [a probabilidade d] esse evento como $=0$. [...] A relação entre procura e oferta explica, portanto, por um lado, somente os desvios dos preços de mercado em relação aos valores de mercado e, por outro, a tendência à anulação desses desvios, isto é, à anulação do efeito da relação entre procura e oferta” (Marx, 1983b, p. 146).

Para entender a dificuldade que esse modo "antigo" de pensar a formação de preços na economia capitalista apresenta para a compreensão do economista "moderno" é preciso fazer um exercício de microeconomia comparada. É necessário contrastar cuidadosamente os modos marxiano e neoclássico contemporâneo de pensar a formação de preços. De um modo preliminar, pode-se adiantar que a diferença crucial entre esses modos reside no seguinte: seguindo os grandes economistas políticos clássicos, Smith e Ricardo especialmente, Marx pensava a gênese de preços por meio de leis de movimento inerentes ao sistema econômico como um todo; já os atuais economistas neoclássicos fazem análise de coerência e, por isso, raciocinam de maneira estática com base em funções de oferta e de demanda, que sempre definem equilíbrios. Mas essa consideração, ainda que central, é bem insuficiente para uma boa compreensão do problema. Destarte, faz-se necessária uma exposição detalhada de ambas as concepções teóricas visando à mencionada comparação.

O confronto entre os modos marxiano e neoclássico atual de pensar a formação de preços levará à conclusão de que subsiste uma diferença profunda entre eles e que esta pode ser sintetizada no contraponto conceitual entre duas espécies de microeconomias, uma delas a que cabe chamar de reducionista e uma outra a que se deve denominar de sistêmica ou evolucionária (Prado, 2006). Ainda que educativa e interessante por si mesma, essa comparação, que atravessa o artigo como um todo, não pode ser o fim da investigação. Ao mergulhar na questão teórica e metodológica, as duas primeiras seções deste artigo revelarão também a inadequação da representação por meio de sistemas de equações como meio de apreender o sistema econômico como processo que 
se desenvolve no tempo. Em conseqüência, essa comparação vai se configurar como um caminho para o desenvolvimento de um modo mais adequado de representar o sistema econômico apreendido como evolver sistêmico e as suas leis tendenciais de movimento.

Seguem-se três seções: o mercado como coerência, o mercado como equilibrismo e o mercado como processo. Na primeira, trata-se do modo como a teoria neoclássica contemporânea apresenta a formação de preços, buscando-se revelar alguns de seus aspectos menos discutidos, principalmente em suas versões didáticas, sempre mais divulgadas. Na segunda seção, procura-se desenvolver um modelo de formação de preço com base no suposto de que os agentes têm racionalidade limitada, sem dispensar, no entanto, as noções de função de oferta e de função de demanda. Havendo notado os problemas que esse segundo modo traz, na seção seguinte busca-se criar um modelo simples de formação de preços que respeita a concepção de sistema econômico como processo. Ao fazê-lo, apresenta-se um entendimento da formação de preço em que as considerações de Marx apresentadas no primeiro parágrafo deste artigo se tornam compreensíveis. Ao final, sintetizam-se os resultados.

\section{MERCADO COMO COERENNCIA}

Para entender como a teoria neoclássica atual pensa a formação de preços, tenha-se em mente de início, como é usual, o mercado de apenas um bem. Para as considerações conceituais que virão após os primeiros passos será necessário raciocinar em contexto de equilíbrio geral.

A teoria neoclássica contemporânea - que rigorosamente deve ser classificada como neo-walrasiana já que deve muito mais a Walras do que a Marshall - faz de início uma distinção analítica entre o "lado" da oferta e o "lado" da demanda, supondo que esses "lados" sejam independentes entre si. Caso isto não ocorresse, de tal modo que mudanças na demanda, por exemplo, pudessem afetar a oferta e vice-versa, então a formulação teórica não conseguiria superar as circularidades; surgiriam indeterminações que minariam a própria formulação enquanto tal.

Em seqüência, essa corrente de pensamento faz distinções entre demanda e quantidade demandada e entre oferta e quantidade ofertada. As funções de demanda e de oferta são derivadas por meio de otimizações levadas a efeito por consumidores e produtores, respectivamente. Esses agentes otimizam de modo independente uns dos outros, mas o resultado coletivo terá de se tornar de conhecimento comum. A função demanda relaciona os preços possíveis de uma determinada mercadoria com as quantidades ótimas que os consumidores desejariam adquirir em cada preço (por 
unidade de tempo e mantidas as demais condições constantes, ou seja, renda, gosto, outros preços etc.). E a oferta consiste numa função que relaciona os preços possíveis dessa mercadoria com as quantidades ótimas que seriam ofertadas pelos produtores a esses preços (mantidas igualmente todas as outras condições constantes, ou seja, a tecnologia, preços dos insumos etc.). Define-se, então, como preço de mercado aquele determinado pela intersecção da oferta com a demanda; nesse ponto a quantidade ofertada coincide com a quantidade demandada e ambas são ótimas. Assim, o equilíbrio é também um ótimo.

A Figura 1 apresenta o plano do preço unitário e da quantidade por unidade de tempo de um bem qualquer. OO é curva da oferta e DD é a curva da demanda desse bem. $\mathrm{O}$ equilíbrio, encontro de ambas as curvas, está indicado pelo par $\mathrm{p}^{\mathrm{e}} \mathrm{e}$ por $\mathrm{q}^{\mathrm{e}}$.

\section{FIGURA 1}

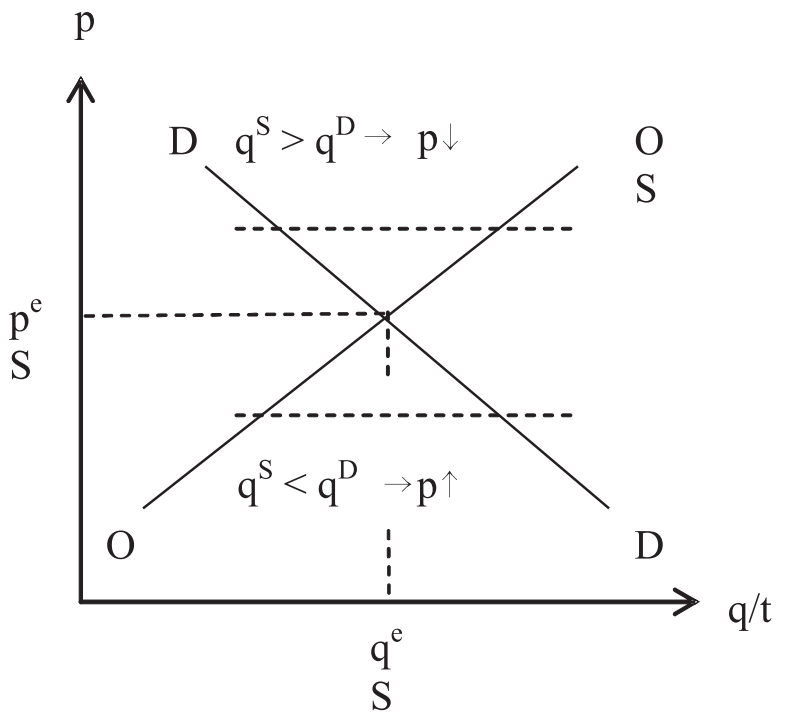

Com base nesse modo de pensar, a teoria econômica contemporânea considera a igualdade da quantidade ofertada e da quantidade demandada como algo corriqueiro, pois todo preço possível implica imediatamente a coincidência entre essas duas quantidades. Assim, todas as transações mercantis ocorrem em equilíbrio e todo preço de mercado que realmente possibilita as transações vem a ser um preço de equilíbrio.

Mesmo raciocinando em equilíbrio parcial, costuma-se associar à fixação do preço de mercado uma dinâmica de formação de preço, inspirada no chamado tâtonnement walrasiano. Quando há excesso de demanda, ocorre escassez no mercado do bem considerado e o preço de fechamento das transações tende a subir; em caso contrá- 
rio, se há excesso de oferta, ocorre abundância e o preço de equilíbrio tende a cair. Entretanto, ainda que os livros didáticos não tratem disso com clareza, esse modo de ajustamento não se refere a um processo de gênese que ocorre efetivamente no mercado. Isto porque nada pode acontecer nesse lugar abstrato onde as trocas supostamente acontecem antes que o preço de equilíbrio seja concertado com exatidão pelos participantes do mercado.

Não há aqui um verdadeiro processo de mercado, mas sim uma dinâmica que tem a natureza de um processo seqüencial de raciocínio ${ }^{1}$ que acontece num tempo meramente lógico. ${ }^{2}$ Para que todos os desacordos sejam eliminados, ou seja, para que haja equilíbrio - nessa teoria não há transação fora do equilíbrio - o preço de mercado considerado tem de subir ou descer dependendo se o excesso é de demanda ou de oferta. Por meio da subida ou da descida dos preços, supóe-se que todos os excessos possam ser eliminados, instalando-se o equilíbrio. Tudo isso, entretanto, é simplesmente um processo idealizado por meio do qual a informação necessária se difunde plenamente para os participantes do mercado, tornando possível a compatibilidade dos planos. E assim tem de ser, pois o pleno conhecimento é um requisito lógico dessa definição de equilíbrio.

Dito de outro modo, essa "dinâmica" - agora, o termo merece ser posto entre aspas - é concebida mantendo os olhos bem fixos no ponto de equilíbrio. Ela apenas expressa a idéia de que os agentes econômicos são miraculosamente capazes de coordenar perfeitamente as suas decisões, mesmo atuando de um modo não-cooperativo. $\mathrm{Na}$ verdade está-se pressupondo o que se deveria demonstrar, ou seja, que tudo se torna imediatamente de conhecimento comum - e assim, também, o equilíbrio. "Nas apresentações usuais da análise de equilibrio" - diz Hayek -, "parece que as questões relacionadas à emergência do equilibrio já foram resolvidas. Mas, ao se atentar bem, logo se torna evidente que essas aparentes demonstraçôes não são mais do que provas aparentes do que já havia sido antes assumido.” (Hayek, 1948, p. 45).

Por que a teoria neoclássica pensa dessa maneira, colocando-se num mundo construído pelo entendimento em que os agentes têm racionalidade substantiva, maximizam metas distintas e claras, em que as expectativas e o conhecimento de si mesmos e do ambiente são perfeitos? Ao contrário do que pode parecer à primeira vista, essa teoria não visa fazer compreender como os mercados funcionam, mas, supondo desde logo que são eficazes e eficientes, dedica-se de modo consciente a apreender apenas a

1 No contexto da teoria dos jogos deliberativos, Binmore chamou de edutivo esse tipo de processo, enfatizando que se baseia apenas em "raciocínio cuidadoso dos jogadores" (Binmore, 1987). Lembre-se que eduzir significa extrair o que está implícito, não por dedução. Mesmo nessa perspectiva, põe-se ainda o problema de saber se é possível derivar a dinâmica de ajustamento dos preços de um comportamento maximizador (Boland, 1986, cap. 9).

2 Ver Robinson (1978). 
coerência possível que possam ter. Ao invés de examinar aquilo que emerge de comportamentos adaptativos sob condições mutáveis, inclusive em razão dos próprios comportamentos, pergunta que espécies de decisões, estratégias e expectativas individuais são consistentes com resultados coletivos que eliminam quaisquer incentivos para a mudança dos próprios comportamentos individuais. ${ }^{3}$ E esse modo de teorizar se mantém tanto na teoria de equilíbrio geral, na teoria dos jogos deliberativos, quanto na economia das expectativas racionais (Brian Arthur, 2005).

Enquanto método de explanação científica, esse modo de apreender as situações econômicas não-cooperativas é reducionista. E por reducionismo entenda-se aqui o preceito metodológico que manda buscar a explicação de qualquer fenômeno nos elementos - e somente nesses elementos - do todo em que aparece. Dado um fenômeno que se deseja explicar, tal como, por exemplo, o preço de mercado de determinado bem, dados os fatores exógenos, busca-se apresentá-lo como efeito de decisões e planos dos agentes que formam o mercado em consideração. Esses agentes são tomados como átomos indivisíveis, estáveis, consistentes e completos. Devidamente distinguidos como consumidores e produtores, passam a responder respectivamente pela demanda e pela oferta do bem em questão. As suas decisões, que permanecem exteriores entre si, são partes de um plexo coletivo; se elas podem ser agregadas de modo consistente, temse a explanação do fenômeno considerado, em particular, do preço de mercado. Para tanto, as propriedades dos indivíduos devem ser cuidadosamente especificadas de tal modo que a agregação possa resolver também, ao mesmo tempo, um problema de coordenação (Prado, 2006).

Esse modo de representar um sistema como um estado e de apreender a realidade como harmonia pré-estabelecida encontra sua forma adequada num sistema de equações simultâneas que é normalmente construído no campo e na perspectiva da teoria dos conjuntos. ${ }^{4}$ Essa formulação já é a expressão matemática - e, portanto, altamente abstrata - de um problema de coerência: fornecidas as formas funcionais, especificados os parâmetros que entram nas equações, que valores das variáveis ou incógnitas - essa é a questão - tornam o sistema isento de contradição? Para que as decisões, estratégias e expectativas de um conjunto de agentes atomizados possam ser apreendidas desse modo é preciso supor que seus comportamentos possam ser expressos em funçóes de reação exaustivas, contínuas, infinitas e preferencialmente diferenciáveis. Apenas assim tudo se torna adequado para que o método reducionista possa fazer o seu trabalho, resolvendo o problema posto pela ambição desmedida da razão dedutivista.

3 A compreensão da teoria econômica contemporânea é dominada pelo convencionalismo - doutrina metodológica que sustenta a validade da teoria na coerência lógica e não em sua adequação empírica ou em seu realismo (Boland, 1992, p. 36).

4 Nesse caso, o conceito de função vem a ser definido como "aplicação", ou seja, como $f: A \rightarrow B$ em que $A \subset R^{m}$ e $B \subset R^{n}$. (Velupillai, 2004). 
O foco na agregação consistente dos comportamentos, ou seja, no seu exato balanceamento, encontra a sua expressão nas provas de existência. Considerando as características e propriedades atribuídas de início aos (a rigor, denominados impropriamente) agentes, a função extraordinária das provas de existência neste tipo de teoria é mostrar que a consistência das decisões, planos e expectativas é formalmente possível. Mesmo no interior dessa construção tautológica, entretanto, a possibilidade formal não é ainda possibilidade efetiva. As provas de existência no contexto da análise de equilíbrio geral têm de ser complementadas com argumentos ou refinamentos que garantam a unicidade e a estabilidade de equilíbrio; todavia, que fique registrado, diante do problema de justificar de um modo edutivo a consistência dos planos, as provas matemáticas não têm sido bem-sucedidas em geral: pode haver multiplicidade de equilíbrios e a convergência a um equilíbrio determinado não fica garantida. ${ }^{5}$

Mesmo fazendo abstração desses problemas, é preciso ver que também a prova de existência pode ser questionada. Para tanto, é preciso entrar um pouco na teoria da computação.

Como foi visto, todo esse modo de pensar demanda justificações edutivas. De que maneira, porém, agentes podem formar crenças racionais sobre crenças racionais de outros agentes? Como formar expectativas mutuamente consistentes sem cair num problema de regressão infinita ou de circularidade viciosa? Essa dificuldade já era do conhecimento de Morgenstern, em 1935:

Tal formação de crenças "suscita uma cadeia sem fim de reações e contra-reações conjecturais. Essa cadeia não pode ser quebrada por um ato de conhecimento, mas somente por um ato arbitrário - uma resolução. Eis que essa resolução, outra vez, teria de ser prevista pelas pessoas envolvidas. O paradoxo se mantém por mais que alguém queira virar e revirar as coisas. A previsão perfeita e o equilibrio econômico são assim irreconciliáveis entre si” (Morgenstern, 1976, p. 174; Knudsen, 1993).

Ora, o obstáculo contido no processo edutivo de formação de crenças que sustenta os conceitos de equilíbrio da teoria econômica ortodoxa é um velho conhecido da Lógica que recebe o nome de "problema de auto-referência". Como é sabido, esse problema já estava contido numa exclamação paradoxal de Epimênides: "esta sentença que aqui digo é falsa!” Na matemática desenvolvida a partir de Gödel e Turing, conhecida como matemática recursiva ou computacional, o problema lógico da auto-referência costuma

5 Está-se fazendo referência aos teoremas de Sonnenschein, Debreu e Mantel. O primeiro desses autores mostrou pioneiramente, em 1973, que os supostos usuais da teoria de equilíbrio geral não impõem restriçôes suficientes nas funções de excesso de demanda, de tal modo que a estabilidade global do equilíbrio não fica garantida. Uma apresentação interessante dessa dificuldade da teoria neoclássica encontra-se em Soromenho (2000). 
ser traduzido num problema teórico de impossibilidade de computação. Nessa teoria, um problema é dito não-computável quando não existe algoritmo capaz de solucioná-lo num tempo finito. Koppl e Rosser, por exemplo, mostraram ilustrativamente a conexão entre a tese de Morgenstern acima citada e a impossibilidade de computar o equilíbrio de Nash num jogo de par ou impar (Koppl e Rosser, 2002). ${ }^{6}$ A questão, numa perspectiva geral, pode ser tratada aqui apenas de modo superficial.

Grosso modo, a teoria neoclássica formula o problema da formação de preços representando o sistema econômico por meio de um sistema genérico de equações em que as variáveis e os parâmetros estão definidos no campo dos números reais. Enxergando-se como teoria rigorosamente demonstrativa, emprega os teoremas de ponto fixo para provar, com base nos assim chamados axiomas de Arrow-Debreu, a existência de equilíbrio. Ao fazê-lo, pensa implicitamente os preços de equilíbrio como vetor que pode ser computado a partir dos dados do problema, pelo menos em princípio. Ora, tornou-se conhecimento corriqueiro na matemática contemporânea que a imensa maioria dos números reais - números infinitos sem qualquer regra de formação - não é computável. Como o sistema é genérico, no plano teórico da própria construção grande parte dos equilíbrios possíveis topologicamente são possibilidades computacionalmente vazias.

Na construção que caracteriza quanto à forma todo o projeto da teoria neoclássica contemporânea em sentido amplo, como exigência intrínseca do próprio método, a temporalidade dos processos econômicos é simplesmente omitida ou ela é apreendida de um modo irrelevante. Isto se verifica quando as mercadorias são datadas no modelo de equilíbrio geral, quando o tempo participa do sistema de equações como variável exógena, quando o tempo é tomado como um recurso escasso cujo emprego também tem de ser otimizado. Em todos esses casos, o tempo é compreendido do mesmo modo que o espaço, ou seja, como reversível.

O tempo apenas se torna importante na apreensão do sistema econômico quando se foca o seu devir fora do equilíbrio, quando captado em seu funcionamento descentralizado, espontâneo e anárquico. Apenas raciocinando fora do equilíbrio é que os processos podem se mostrar como irreversíveis e as decisões tomadas podem se apresentar como irrevogáveis. Apenas pensando que os processos ocorrem longe do equilíbrio é que pode surgir o fenômeno da dependência de trajetória (Boland, 1978). Nesse caso, as interações descentralizadas têm de ser compreendidas como constitutivas dos próprios agentes - estes aprendem e se transformam com elas - de tal modo que os resultados globais dessas interaçóes em processo vêm a ser propriedades emergentes do próprio sistema. O modo neoclássico contemporâneo de fazer teoria expressa, assim, na elegância tão louvada da construção matemática conjuntista, um horror ao

6 Ver Albin e Foley (1998, p. 73-103) para uma visão geral do problema. 
antagonismo das decisões incoerentes e aos atropelos dos processos desequilibrados que caracteriza o mundo real!

\section{MERCADO COMO EQUILIBRISMO}

O modo marxiano de entender a formação de preço deve muito, evidentemente, aos economistas clássicos, em particular a Adam Smith e David Ricardo. No plano da representação, esse modo - essa tese é aqui defendida - respeita a temporalidade em flecha dos processos econômicos, ${ }^{7}$ configurando-se como sistêmico e evolucionário. ${ }^{8}$ Quer-se mostrar neste artigo que a formação de preço em Marx, ao contrário do que ocorre com aquela formulada pela teoria neoclássica, é consistente com a teoria da computação. O equilíbrio do sistema econômico, mesmo se de ocorrência improvável, tem de resultar de processo efetivo de equilibração que é representável computacionalmente.

Marx, diferentemente da teoria neoclássica, considera os preços de mercado determinados em geral pelas desigualdades entre a oferta e a demanda; em conseqüência, ele pergunta o que há de oculto nessa coincidência possível - outrossim, altamente improvável. Distingue preço de mercado de valor de mercado ${ }^{9}$, afirmando que o enigma da formação de preços se encontra na determinação do valor de mercado, o qual se tornaria efetivo apenas casualmente quando oferta e demanda se encontrassem em equilíbrio. A oferta e a demanda, assim, explicam os desvios dos preços de mercado em relação aos valores de mercado, portanto, o movimento dos preços fora do equilíbrio e a tendência deles a gravitar em torno do equilíbrio. De qualquer modo, para ele, "a relação entre procura e oferta não explica o valor de mercado, mas, pelo contrário, é este que explica as flutuaçôes de procura e oferta” (Marx, 1983b, p. 147).

Caminha-se na compreensão do parágrafo anterior quando se tem em conta que não se encontram em $O$ Capital distinções entre quantidade demandada e função de demanda ou entre quantidade ofertada e função de oferta. Quando aí se fala em oferta ou em demanda deve-se entender, respectivamente, quantidade ofertada ou quantidade demandada, em certo momento e em dadas circunstâncias. Apesar disso, encontramse nesse livro indicações de que prevalece nos mercados relação direta entre oferta e preços e relação inversa entre demanda e preço; por exemplo, na frase seguinte: "no

7 É irônico, mas a seguinte tese de Hayek vem a ser consistente com o modo de pensar de Marx: "como equilibrio é uma relação entre açôes, e como as ações [...] devem acontecer necessariamente no tempo, é óbvio que a passagem do tempo é essencial para dar ao conceito de equilibrio algum sentido" (Hayek, 1948, p. 37).

8 De modo mais geral, sustenta-se a tese de que a cientificidade positiva (ou saber do entendimento) com base na qual trabalha criticamente a dialética marxiana em $O$ Capital é sistêmica e evolucionária.

9 Marx, no capítulo X do livro terceiro de O Capital, emprega o valor de mercado como termo relacionado a preço de produção. 
caso em questão, se o preço fosse mais alto do que o valor médio de mercado, a procura seria menor" (Marx, 1983b, p. 139).

Note-se, em adição, que pensar com base em funções estáveis que retratam comportamentos microeconômicos pressupõe já compreender o mercado - senão como coerência permanente - pelo menos como equilibrismo. E isto contrasta fortemente com a visão de Marx que considera o sistema capitalista como modo metabólico e anárquico de produção social - ou seja, como processo estruturado por relações de produção que se reproduzem por meio de formas em transição e que se apresenta de modo irregular, flutuante, irreversível e dependente de trajetória. Ademais, Marx indicou claramente que concebia a formação de preços como um processo que hoje seria dito estocástico: "a possibilidade de uma incongruência quantitativa entre o preço e a grandeza de valor [...] é a forma adequada a um modo de produção em que a regra somente pode impor-se como lei cega da média à falta de qualquer regra” (Marx, 1983a, p. 92).

Entretanto, um procedimento analítico ${ }^{10}$ - não coincidente, aliás, com o da teoria neoclássica contemporânea - pode ser empregado na obtenção de uma primeira aproximação ao modo de compreender clássico e marxiano do funcionamento dos mercados. Contudo, a tentativa se justifica não tanto pelos aclaramentos que propicia, mas pelas dificuldades que gera e apresenta. Considera-se, então, um mercado em isolamento dos outros mercados e se investiga a formação dos preços nesse mercado. Supõe-se nesta seção que o funcionamento do mercado não seja afetado por aleatoriedade.

Nessa perspectiva, não se supõe que os agentes tenham racionalidade perfeita e que sejam capazes de otimizar. Ao contrário, admite-se que eles desconhecem em larga medida os modos de funcionamento do mercado e que, por isso mesmo, agem adaptativamente, procurando alcançar os seus objetivos, quais sejam, o atendimento do melhor modo possível das próprias necessidades ou a obtenção do maior lucro possível. Eles se movem com base em um conhecimento aproximado sobre os preços, sobre as quantidades ofertadas e demandadas, sobre a qualidade dos produtos, assim como sobre outras condições do mercado. Os seus comportamentos, no entanto, apresentam regularidades, as quais se manifestam agregadamente. Supõe-se, por isso, que tais regularidades microeconômicas resultam em regularidades macroeconômicas.

Os consumidores e os produtores fazem planos de consumo e de produção. Os planos dos consumidores manifestam-se simplesmente como pares de preços e quantidades demandadas; nesses pares, os preços consistem de valores máximos que os consumidores desejam pagar pelas quantidades demandadas. Já os planos dos produtores, que se expressam também em pares de preços e quantidades ofertadas, contêm os preços

10 Esse procedimento foi sugerido pela leitura de um texto de Leijonhufvud sobre o método de análise de Keynes que o apresenta como um marshaliano (2006). Não se pretende aqui, por outro lado, ser fiel a qualquer desses autores. 
mínimos que os produtores querem obter pela venda das quantidades ofertadas. Os planos dos consumidores e dos produtores, em conjunto, formam a demanda e a oferta da mercadoria, respectivamente. Essas funções, entretanto, não refletem decisões projetadas ótimas dos agentes; expressam, outrossim, de forma agregada, os planos conjeturados, possivelmente falhos, dos consumidores e dos produtores. Elas têm, assim, o caráter de uma configuração coletiva de projetos que baliza o funcionamento do mercado enquanto os planos individuais permanecem estáveis.

A situação do mercado pode ser retratada do modo que aparece na Figura 2 (que é apenas ilustrativa). Em face das características do modelo, se há apenas um pequeno número de agentes, tanto a demanda quanto a oferta têm de ser apresentadas na forma de escadas. Como os agentes agora são pouco informados e têm racionalidade limitada, não se pode garantir que os seus comportamentos conjugados sejam coerentes com a configuração de mercado estabelecida por seus planos. O preço vigente pode estar acima ou abaixo daquele que produz o balanceamento do mercado; a quantidade ofertada pode ser excessiva ou insuficiente, de tal modo que a situação observada num dado momento pode não corresponder à de equilíbrio - situação em que as "forças" da oferta e da demanda deixariam de operar. Se ocorrer, entretanto, transação fora do equilíbrio, deixa de existir razão para que os planos permaneçam estáveis.

FIGURA 2

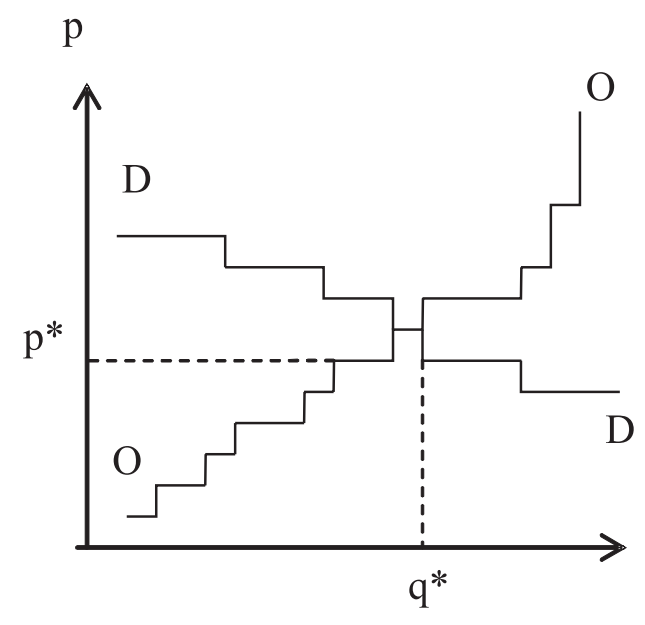

É evidente que a análise do mercado - e de seu ajustamento - depende agora das instituiçôes que regem o seu funcionamento (Lesourne, 1992). Ademais, a análise microeconômica se torna inerentemente dinâmica. É preciso considerar a flecha do tempo, pois as ações individuais e as seqüências dos eventos agregados são dependen- 
tes de trajetória. Supõe-se no que se segue que o funcionamento do mercado ocorre por meio de transações bilaterais e que os produtores tenham um papel ativo na formação de preços.

A Figura 3 a seguir apresenta mais uma vez o plano do preço unitário e da quantidade por unidade de tempo referido a certa mercadoria. O segmento de reta VM, o qual não pode ser entendido como uma função de oferta, representa o valor de mercado. Ele nada mais é do que a expressão monetária da quantidade de trabalho socialmente necessária ${ }^{11}$ para produzir uma unidade da mercadoria no momento considerado. Marx não pressupõe que esse valor seja constante no tempo, mas sustenta, ao contrário, que se encontra em permanente mudança no desenvolvimento do capitalismo. Está aqui fixado, entretanto, por que as causas de sua mudança não estão sendo examinadas. Ademais, VM não pode ser explicado apenas pelas tecnologias de produção da mercadoria, mas vem a ser uma propriedade emergente das interações sociais estruturadas que constituem o próprio sistema econômico como um todo.

Enquanto expressão do valor trabalho, o preço de produção permanece desconhecido aos participantes do mercado. ${ }^{12}$ Marx supõe, entretanto, que ele aparece no processo da concorrência como preço médio que contém uma taxa de lucro média, a qual, por sua vez, figura agora como fonte de compensação de diferenças nas condições de produção dos diferentes setores da economia. "Depois de os preços médios e de os preços de mercado que lhes correspondem terem se fixado por algum tempo, aparece na consciência dos capitalistas individuais que nessa equalização [ou seja, das taxas de lucro] determinadas diferenças são compensadas, de modo que eles as incluem logo em seu cálculo recíproco" (Marx, 1983b, p. 160). Logo, tais preços médios não se referem ao curto prazo, não são simples médias de preços, mas valem como orientação num intervalo de tempo mais ou menos longo.

Enquanto manifestações aparentes do sistema econômico, eles devem figurar na representação de seu funcionamento perceptível, ou seja, na modelagem do modo de ser superficial dos mercados. Note-se que esses preços médios funcionam como preços nocionais, que permitem aos produtores capitalistas individuais, assim como aos consumidores em geral, se posicionarem diante das condições objetivas dos mercados. Cada um dos primeiros, assim, pode aferir se a taxa de lucro por ele obtida é alta ou baixa; cada um dos consumidores pode julgar se o preço de determinada mercadoria que está sendo ofertada no mercado é alto ou baixo. Assim, o valor de mercado VM,

11 Ao se considerar a existência de diferentes composições orgânicas do capital, a lei do valor se transforma em lei do preço de produção.

12 "O que a concorrência não mostra é a determinação de valor, que domina o movimento da produção; esses sãa os valores que estão atrás dos preços de produção e que, em uiltima instância, os determinam” (Marx, 1983b, p. 159). 
enquanto aparência, deve ser devidamente reinterpretado como o preço médio nocional do mercado em consideração. ${ }^{13}$

FIGURA 3

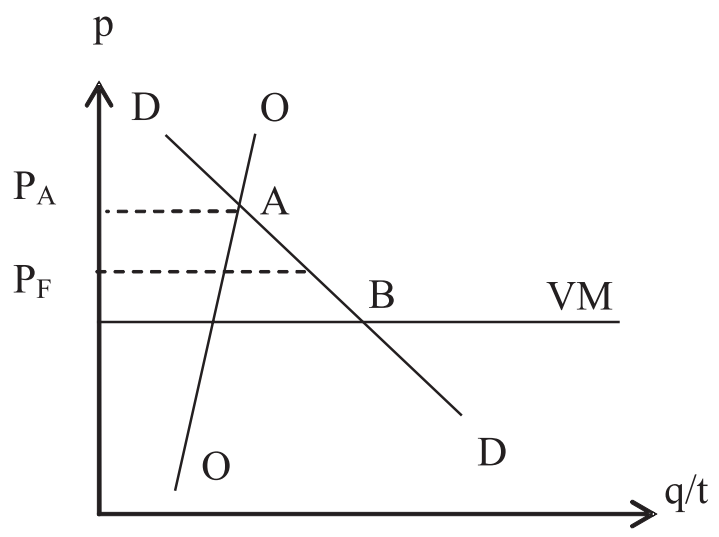

A semi-reta $\mathrm{OO}$ que aparece na figura, em conseqüência, apresenta graficamente os planos de oferta dos produtores num momento do mercado e DD indica os planos dos consumidores, ambos considerados coletivamente.

A oferta representada na figura por OO é posta pela reprodução do capital, pelo movimento que comanda a alocação da força de trabalho e, assim, o dispêndio de trabalho entre as diferentes esferas da produção. Eis que a reprodução do capital normalmente em escala ampliada ocorre de modo descentralizado por meio da concorrência dos capitais. E isto somente acontece por meio de flutuações permanentes: ora o mercado se encontra excessivamente abastecido ora ele se encontra insuficientemente aprovisionado. Acima de VM, pelo menos para alguns capitalistas, há superlucro e este surge em decorrência da subprodução do bem em consideração num momento anterior; o lucro excedente ao normal suscita aumento do investimento no setor, o que produzirá uma tendência ao aumento da produção; abaixo de VM há superprodução e, assim, sublucro pelo menos para os capitalistas mais ineficientes; a queda do investimento decorrente gerará tendência para a redução da produção. Dado o comportamento da demanda, o aumento ou a diminuição da produção faz o preço de mercado cair ou subir, respectivamente. Daí que o valor de mercado (VM) seja "o centro em torno do qual as flutuaçôes da procura e da oferta fazem oscilar os preços de mercado" (Marx, 1983b, p. 140).

13 Os produtores e consumidores, entretanto, não sabem que os preços nocionais são de equilíbrio. Na prática, como se sabe, são valores imprecisos. A informação de que são preços de equilíbrio, por um lado, lhes seria totalmente inútil. Por outro lado, se um coletivo dos agentes ou o Estado tentasse coordenar as ações individuais com base nesses preços, ele provavelmente fracassaria. 
A Figura 3 retrata um momento do mercado. Suponha-se que os preços pedidos pelos produtores se situem em $\mathrm{P}_{\mathrm{F}}$. Nesse caso, há excesso de demanda, de tal modo que o preço tenderá a subir. Como o mercado funciona por meio de encontros bilaterais entre vendedores e compradores, haverá necessariamente trocas fora do equilíbrio. Como as transações fora do equilíbrio podem alterar os planos dos agentes, nada garante que o ponto A possa permanecer como o atrator momentâneo do sistema.

Mesmo se o ponto A continua sendo um ponto de atração, ele apenas pode ser visto como aquele em que haveria balanceamento momentâneo do mercado. Se a economia porventura se situasse sobre esse ponto, a oferta e a demanda ainda se encontrariam em conflito. Se isto não se afigura plausível para o economista contemporâneo acostumado a pensar estaticamente, perceba-se que para Marx o ponto A poderia ser visto como de equilíbrio instável, ou seja, como situação que contradiz a lei tendencial de movimento regedora da formação de preços - o que, aliás, está implícito na própria noção de gravitação.

Enquanto um evento raro e apenas transiente, o equilíbrio verdadeiro só poderia ocorrer para Marx no ponto B em que a oferta e a demanda se igualariam, satisfazendo-se mutuamente. Assim "o intercámbio ou a venda das mercadorias por seu valor é o racional, a lei natural de seu equilibrio” (Marx, 1983b, p. 145). O equilíbrio aqui não é concebido como decorrente da consistência intencional de planos dos agentes, mas como coerência eventual produzida pelo operar tateante do próprio sistema econômico. Daí que Marx possa chegar à conclusão inesperada de que esse último equilíbrio explica os desvios dos preços de mercados e não, inversamente, que se possa explicar este equilíbrio por meio dos desvios, ou seja, por meio da interação entre oferta e demanda.

Além da instabilidade necessária dos planos quando a economia opera fora do equilíbrio, aqui começam a aparecer outras limitações do método analítico empregado nessa seção para compreender de modo preliminar as concepções de Marx sobre a formação de preços. Para ele, os preços de mercado e os valores de mercado das diversas mercadorias são co-determinados em processo. As flutuações dos preços de mercado das mercadorias, flutuações essas afetadas por aleatoriedade, assim como a mobilidade da força de trabalho e a alocação social do trabalho nas diferentes esferas da produção, são condições fenomênicas para a formação subjacente e essencial dos valores de mercado. Daí que os valores de mercado determinados pelas quantidades socialmente necessárias de trabalho se imponham ao próprio funcionamento do mercado como lei natural cega.

A interpretação oferecida nesta seção atendeu às pré-concepções dos economistas contemporâneos. Porém, ao final mostrou-se inadequada para representar o mercado enquanto manifestação do metabolismo complexo do capital. De fato, pode-se ar- 
gumentar que não se afasta suficientemente do modo de representação reducionista e mecânico. ${ }^{14}$ Ainda que produza melhor compreensão do mercado, já que trata de seu funcionamento - e não apenas de sua coerência - gera análises inconsistentes: a estabilidade das funções demanda e oferta entra em contradição vulgar com as trocas fora do equilíbrio.

Marx diz que as determinações quantitativas da necessidade social e da produção no sistema capitalista são completamente elásticas e oscilantes. A fixidez das determinações quantitativas - diz - é mera aparência (Marx, 1983b, p. 145). O caráter sistêmico e metabólico que enxerga nesse sistema se manifesta com grande força expressiva e retórica no trecho que se segue e que fecha esta seção:

"Se a procura e a oferta determinam o preço de mercado, por outro lado, $o$ preço de mercado e - levando-se a análise mais longe - o valor de mercado determinam a procura e a oferta. [...] A essa confusão - determinação dos preços por procura e oferta e, ao mesmo tempo, determinação de procura e oferta pelos preços - acresce que a procura determina a oferta $e$, inversamente, a oferta a procura, que a produção determina o mercado, e o mercado a produção.” (Marx, 1983b, p. 147)

\section{MERCADO COMO PROCESSO}

Ainda que sugestivo, o método acima empregado é bastante inadequado para representar o modo clássico e marxiano de apreender a formação de preços na economia capitalista. O seu principal defeito é não articular de forma satisfatória o nível microeconômico com o nível macroeconômico. As ações de procura dos consumidores e de oferta dos produtores não se encontram explicitamente ligadas ao andamento temporal dos preços de mercado e das quantidades aí vendidas. Em conseqüência, um novo método tem de ser considerado e este deve necessariamente apreender a formação de preços explicitamente como processo dinâmico, temporalmente orientado, por meio de algoritmo computacional. ${ }^{15}$

Para tanto, antes de mais nada é preciso abandonar o modo de pensar fundado nas funções neoclássicas de oferta e demanda; essas relações são construídas sob supostos

14 Entenda-se aqui concepção mecânica aquela em que os fenômenos são explicados de modo determinista por meio de antecedentes causais invariáveis, sem a interferência de qualquer finalismo sistêmico ou qualidade essencial. Concepção metabólica, por sua vez, é aquela que enxerga os fenômenos como expressões de processos vivos cuja essência vem a ser a assimilação e a desassimilação de substâncias; no caso do processo metabólico do capital trata-se de absorção e consumo produtivo e improdutivo de trabalho.

$15 \mathrm{O}$ mercado, assim, é representado por um algoritmo; porém, isto não implica que se suponha que o mercado real possa ser compreendido, redutivamente, como um algoritmo (Koppl, 2007). 
muito restritivos os quais enviam a análise para o céu azul da tautologia. A idéia de que consumidores e produtores - pessoas, famílias, empresas etc. - formulam planos de transação para cada preço possível precisa ser repelida. A noção de que os agentes em geral mantêm planos estáveis conforme o processo de mercado tem andamento também deve ser rejeitada. Isso é necessário para poder pensar a formação de preços como manifestação em processo do metabolismo do capital. Apenas as noções de quantidade demandada e quantidade ofertada são suficientes para formular uma boa compreensão do funcionamento do mercado ao modo de Marx. Ademais, é preciso admitir que as transações pontuais que ocorrem no mercado são afetadas por aleatoriedade de tal modo que o sistema econômico deixe de ser compreendido ao modo de Laplace. ${ }^{16}$ Em suma, é preciso assumir explicitamente o caráter evolutivo do sistema econômico.

O objetivo desta seção é, portanto, representar a formação de preços de um modo que se afasta da teoria neoclássica e que se aproxima da teoria clássica e marxiana.

Assim, por exemplo, Marx afirma textualmente que a demanda decorre da estrutura social e da configuração de forças prevalecentes de forma conjuntural na sociedade. A demanda, pois, é regulada pela 'necessidade social', mas esta é condicionada de modo essencial pelas relações das diversas classes entre si e por sua respectiva posição econômica. Donde decorre que essa própria necessidade é regulada pela repartição do valor adicionado entre lucro e salário e pela subdivisão do lucro em lucro industrial, juros, renda fundiária, impostos etc. (Marx, 1983b, p. 14l). É claro que os desejos ou as preferências individuais também influem nas quantidades socialmente demandadas de mercadorias, mas esses próprios desejos e preferências estão em larga medida condicionados pelo processo social - em particular, por exemplo, pela propaganda. No capitalismo em estágio avançado, os consumidores passam mesmo a ser produzidos pelos produtores de mercadorias.

Prosseguindo nessa linha de pensamento, há ainda outras características importantes que devem ser obedecidas por uma representação cientificamente adequada do processo de mercado, tal como aparece em $O$ Capital. Para uma boa articulação do nível das ações com o nível dos resultados coletivos não basta modelar explicitamente como os elementos do sistema agem É necessário considerar as relações por eles travadas, assim como os modos específicos pelos quais as suas ações e relações se compõem. Isto porque os fenômenos globais em geral decorrem não só do modo de atuar dos indivíduos socializados (que não são átomos, mas elementos de uma totalidade), mas

16 Na esfera da Mecânica, Laplace, numa passagem famosa, declarou que para uma inteligência dotada de racionalidade perfeita, ciente, pois, da posição de todas as partículas materiais e das forças agindo entre elas, "o futuro assim como o passado estaria diante de seus olhos" (apud Nagel, 1961, p. 281). 
também da estrutura social subjacente que embasa os modos pelos quais estão organizados. É evidente que se deve pensar os agentes, por realismo representacional, como seres dotados de limitada racionalidade instrumental. $\mathrm{O}$ que significa dizer que eles têm um conhecimento imperfeito do ambiente em que atuam e que agem tendo por referência principalmente a própria situação local; de modo contrário, não se pode supor que consumidores e produtores tenham um conhecimento global e pleno do mercado como um todo.

De um modo essencial, torna-se necessário construir agentes que aprendem e que são afetados pelos resultados de suas próprias ações no ambiente de atuação e, em especial, no que se refere à consecução de seus objetivos. Sendo assim, as conseqüências intencionais e não intencionais das ações devem realimentar as motivações e os planos dos agentes de tal modo que os resultados possam ser dependentes de trajetória. Esses agentes não devem ser construídos como tipos, mas como membros de populações, as quais, em princípio, são heterogêneas nos aspectos relevantes considerados. As ações têm, pois, conseqüências não intencionadas. Isto implica que os seus resultados coletivos podem se configurar como propriedades emergentes. A composição em processo das ações, por outro lado, apresenta assim a propriedade da auto-organização, ressalvando-se desde já que não se associa a essa característica nenhum elogio ao mercado. De qualquer modo, considerando os agentes como capazes de tomar iniciativas no que se refere à descoberta de alternativas disponíveis, o modelo deve ser capaz de apresentar desempenho caracterizado pela novidade permanente de tal modo que o estrito equilíbrio, se existe, seja apenas uma probabilidade remota. ${ }^{17}$

Em síntese, julga-se que a concepção marxiana de formação de preço pode ser captada por meio daquilo que tem sido chamado de modelo de agentes (agent-based computational model), dentro da compreensão do sistema econômico como sistema complexo. Para tanto, é preciso formular modelos matemáticos de sistemas dinâmicos - caracteristicamente não-clássicos. ${ }^{18}$ Está-se admitindo que esse modo de ver o mercado capitalista é consistente com as formulações teóricas dos autores dessas duas correntes articuladas de pensamento econômico. Essa leitura está baseada na suposição adicional de que autores como Smith, Ricardo e Marx não dispunham de recursos matemáticos para expressar as suas concepções formalmente. ${ }^{19}$

17 Aqui o modelo estará interessado na representação do processo de formação de preços, mas em geral esse tipo de modelo tem de deixar um lugar importante para as instituições (regras, convençóes, leis etc.). Mirowski chamou este tipo de modelo de mercatômato (tradução de markomata) (Mirowski, 2007).

18 Os sistemas dinâmicos clássicos são formados por equações diferenciais ou por equaçôes a diferenças finitas, instrumentos tradicionais do cálculo diferencial e integral. Os não-clássicos são sistemas recursivos formados por algoritmos que expressam alta complexidade combinatória e dinâmica, permanecendo ainda finitos. Pertencem à esfera da matemática recursiva em que se definem funções como "regras, procedimentos ou conjunto de instruçóes para realizar uma tarefa" (Velupillai, 2004)

19 A propósito, pensar a transformação de valores em preços fazendo uso da análise matemática, por meio dos chamados sistemas duais, foi o pecado original responsável pelos descaminhos do centenário debate sobre o problema da transformação (Souza, 2004). 
Como ilustração, constrói-se abaixo um modelo simples de um sistema econômico ${ }^{20}$ formado por apenas dois mercados; neles se comercializam bens que, por isso, adquirem a forma de mercadoria. Desse mercado participam $m$ produtores e $n$ consumidores, devidamente ordenados pelos números naturais positivos. Os $m / 2$ primeiros capitalistas produzem a mercadoria 1 e os $m / 2$ seguintes produzem a mercadoria 2 , e o fazem apenas contratando força de trabalho; por suposição simplificadora extrema, a produção nessa economia não requer meios como insumos, máquinas etc. Todos os consumidores - conjunto formado pelos trabalhadores empregados e pelos capitalistas - querem sempre comprar ambas mercadorias para garantir a própria sobrevivência em sociedade. Nem todos os trabalhadores disponíveis, porém, encontram-se empregados. Aqueles rejeitados pelo sistema formam o exército industrial de reserva. Os componentes desse contingente sobrevivem supostamente por meio das doações de mercadorias advindas de programas Fome-Zero, organizados pelos capitalistas.

As unidades de tempo do modelo vêm a ser "momento", "fase" e "vida". Momento é o instante do tempo em que ocorre uma transação. Fase é o tempo necessário para que todos os agentes tenham uma oportunidade de transacionar. Vida é o tempo total de funcionamento do mercado, formado por uma sucessão finita de fases.

Cada produtor é definido por seu número $k$. Em cada fase, ele oferta uma determinada quantidade de mercadoria fixando determinado preço. Sejam $p_{i k}^{S}(t), i=1,2$ e $k=$ $1,2, \ldots, m$, estes preços de oferta. Eles são ajustados adaptativamente no processo de mercado, mas apenas podem mudar de uma fase para outra, dentro do tempo de vida do mercado. Um preço $p_{i k}^{S}(t)$ é um mínimo desejado pelo produtor $k$ no momento t. Em conseqüência, o preço de fechamento da transação deverá ficar acima desse mínimo em virtude da barganha que ocorre no momento da venda.

Para focar o metabolismo inerente à formação de preços em isolamento das transformações das forças produtivas, supõe-se que os dois bens sejam produzidos com tecnologias de coeficientes fixos. Isto equivale a admitir que a produtividade do trabalho se mantenha constante nos dois setores durante a vida do mercado. Sejam $l_{i k}, i=1$, 2 e $k=1,2, \ldots ., m$, os coeficientes de trabalho de cada empresa. Sejam $l_{1}$ e $l_{2}$ as quantidades médias de trabalho necessárias para produzir uma unidade de cada um dos bens 1 e 2 .

Admite-se, em seqüência, que o salário - indicado por $w$ - está fixado nominalmente por contratos coletivos de longa duração válidos para a economia como um todo, de tal modo que os ajustes adaptativos feitos pelos produtores de mercadorias se restrin-

20 Esta parte do artigo é inspirada nos modelos de formação de preços construídos por Lesourne (1992). Os modelos encontrados em seu livro, ainda que construídos na perspectiva da teoria do valor subjetivo, contradizem as visões tradicionais walrasiana ou neo-walrasiana e neo-ricardiana. 
jam às alterações nos preços de oferta. Estes preços variam, em princípio, de empresa para empresa. A variável de decisão de cada capitalista é, pois, a taxa de lucro que é fixada numa fase para valer na fase seguinte do curso do mercado. Estabelecida essa última taxa ${ }^{21}$, fica definido em cada fase de produção, para cada setor $i$ e cada empresa $k$, um preço de oferta.

$$
l_{i k} w\left[1+r_{i k}(t-1)\right]=p_{i k}^{s}(t)
$$

Os valores sociais ou de mercado - forma aparente dos preços de produção das mercadorias $^{22}$ - serão indicados por $p_{i}^{N}, i=1,2$. Tais preços não decorrem diretamente das escolhas dos agentes; de modo diferente, segundo a teoria clássica e Marx, são determinados intrinsecamente pelo metabolismo do sistema econômico do capital. Dadas as suposições feitas sobre as tecnologias de produção, postos entre parênteses os modos de organização da produção, permanecem constantes durante todo tempo de vida do sistema considerado. Ademais, pressupondo como conhecido o valor intrínseco do dinheiro e o padrão monetário em vigor, pode-se admitir que apareçam para os agentes como $p_{1}^{N}$ e $p_{2}^{N}$, ou seja, como preços de referência que informam o comportamento dos vendedores e dos compradores de mercadoria. Na implementação do modelo, supõe-se formalmente que $p_{1}^{N}=\varphi l_{1}$ e $p_{2}^{N}=\varphi l_{2}$, onde $\phi$ é um parâmetro que faz a conversão do valor em preço. ${ }^{23}$

Cada consumidor é definido por seu número $j$. Em cada fase, ele demanda certas quantidades das duas mercadorias, estimando preços máximos que deseja pagar por unidades de cada uma delas. Tais preços de demanda, indicados por $p_{i j}^{D}$, sendo $i=$ 1,2 e $j=1,2, \ldots ., n$, são ajustados adaptativamente no processo de mercado. Não variam em cada fase, mas podem mudar na passagem de uma fase para outra. Note-se também, desde já, que o preço de fechamento da transação poderá ser menor do que o preço da demanda em virtude do processo de barganha que ocorre nas transações bilaterais.

Cada consumidor, em cada fase, dispõe de uma renda $y_{j}(t)$ que sempre é inteiramente gasta na compra dos bens da economia - ainda que não necessariamente na mesma fase em que é recebida. Destina parte dessa renda, ou seja, $\alpha_{j} y_{j}(t)$, ao consumo de

21 Na implementação, a taxa de lucro de cada empresa é fixada com certa arbitrariedade como condição inicial de funcionamento do modelo.

22 Ver Carcanholo (2007, p. 98-118).

23 A transformação de valores em preços de produção é feita pelo processo social cegamente, refletindo-se na superfície do sistema, segundo Marx, por meio de preços médios. Como aqui se trabalha estritamente no plano da representação, é necessário fazer a suposição de que esse parâmetro seja conhecido. Outrossim, segundo Marx, o processo social é dialético e, como tal, não pode ser apresentado completamente pela matemática, já que esta nunca deixa de ser analítica. 
I e a parte restante, ou seja, $\left(1-\alpha_{j}\right) y_{j}(t)$, ao consumo de 2. Por simplicidade, $\alpha_{j} \in[0,1]$ é tomado como fixo na fase. Como o preço de fechamento de cada transação pode ser menor do que o preço de demanda, a quantidade efetivamente adquirida da mercadoria poderá ser maior do que aquela planejada.

Entre os consumidores, existem trabalhadores e capitalistas. Há $r$ trabalhadores indexados pelos números naturais e nem todos encontrarão emprego. Se o volume gerado de produção em certa fase requerer $s(t-1)$ trabalhadores $[s(t-1)<r]$, serão pagos $s(t-1)$ salários ao final dessa fase. Sem perda de generalidade, supõe-se que os $s(t-1)$ primeiros trabalhadores estiveram empregados e receberam tal salário. A renda desses trabalhadores consumidores na fase seguinte será igual a $y_{j}(t)=w, j=1,2, \ldots, s$. A renda dos trabalhadores desempregados é nula, ou seja, $y_{j}(t)=0, j=s+1, s+2, \ldots, r$. Há também $m$ capitalistas e estes estão reordenados em seqüência enquanto consumidores ( $\operatorname{com} r+m=n$ ). A renda de cada um deles, em cada momento, é dada pelo lucro total obtido na própria empresa no momento anterior. Para calculá-lo, é preciso saber o montante vendido de mercadoria, indicado por $\bar{q}_{i j}^{S}(t-1), \quad j=r+1, r+2, \ldots, n$. De todo modo, tem-se que a renda de cada capitalista pode ser calculada.

$$
y_{j}(t)=l_{1} w \bar{q}_{i j}^{S}(t-1) r_{i j}(t-1)
$$

Todos os agentes conhecem as qualidades dos bens comprados e vendidos. Ambos os bens são perecíveis e não duram mais do que uma fase. Se $q_{i j}^{S}(t-1)$ é o montante produzido, então $q_{i j}^{S}(t-1)-\bar{q}_{i j}^{S}(t-1)$ vem a ser o desperdício ocorrido na fase considerada, o qual é inerente ao funcionamento do mercado. Os contratos de compra e de venda são pontuais. Os valores de uso comprados como mercadoria são imediatamente consumidos.

Os produtores e os consumidores estão sempre presentes no mercado, respectivamente, como vendedores e compradores. Em cada fase, cada um dos consumidores tem a oportunidade de adquirir as quantidades planejadas de cada uma das mercadorias. Para tanto, têm de escolher, primeiro, um produtor de bem 1 e, depois, um produtor de bem 2, realizando, assim, dois encontros bilaterais. Se uma compra pretendida não ocorre, o consumidor terá nova oportunidade de adquirir essa mesma mercadoria apenas na fase seguinte. A renda assim poupada em uma fase é acumulada para ser gasta na mesma mercadoria, na fase seguinte. Em menor número do que os consu- 
midores, os produtores podem vender para vários deles, com diferentes preços de fechamento.

Em cada fase acontece uma seqüência de encontros aleatórios entre produtores e consumidores, de tal modo que todos os consumidores tenham oportunidade de comprar as mercadorias desejadas. Em cada encontro, haverá transação se $p_{i j}^{D}>p_{i k}^{S}$ e o preço de fechamento, de acordo com as suposições anteriores, se situará entre esses dois valores, ou seja, $p_{i k}^{S} \leq p_{i k}^{F} \leq p_{i j}^{D}$. A incerteza inerente ao processo de barganha é modelada fazendo com que o preço de fechamento seja aleatório nesse intervalo.

Os preços de oferta e de demanda podem mudar na passagem de uma fase para outra. Um preço de demanda determinado é aumentado na fase posterior sempre que o consumidor não consegue adquirir a mercadoria ao seu referido preço na fase anterior. É reduzido quando o preço de fechamento na fase anterior se situa abaixo de um limiar definido como uma porcentagem $\gamma$ do preço de demanda projetado pelo consumidor. Já a mudança dos preços de oferta de uma fase para outra depende de um limiar definido como certa porcentagem $\beta$ da quantidade produzida pela empresa na fase em consideração. Se a quantidade comercializada for superior ou igual à quantidade produzida, ou seja, se $\bar{q}_{i k}^{S}(t-1) \geq \beta q_{i k}^{S}(t-1)$, então o capitalista aumenta o preço na fase seguinte. Porém, se $\bar{q}_{i k}^{S}(t-1)<\beta q_{i k}^{S}(t-1)$, então ele o reduz. Implicitamente, o investimento flutua e o capital se desloca de um setor para outro, de uma empresa para outra, dependendo do que ocorre com as taxas de lucro.

Os produtores de mercadoria, na busca da máxima remuneração para o capital investido, não só tateiam o funcionamento do mercado regulando a taxa de lucro, mas também o fazem procurando minimizar o desperdício. Assim, a quantidade ofertada de mercadoria $i$ pelo produtor $k$ numa determinada fase é determinada pela quantidade ofertada na fase anterior e por um delta (positivo ou negativo) constituído pela diferença entre a média do preço de fechamento e o preço natural. Sendo $\theta_{i k}(t-1)$ o número de vendas da mercadoria $i$ na fase $\mathrm{t}-1$ feitas pelo produtor $k$, e sendo $\lambda_{i}$ um número positivo próximo de zero, tem-se formalmente:

$$
q_{i k}^{S}(t)=q_{i k}^{S}(t-1)+\lambda_{i}\left(\frac{\sum p_{i k}^{F}(t-1)}{\theta_{i k}(t-1)}-p_{i}^{N}\right)
$$


Essa espécie de modelo apenas pode ser estudada por simulação. ${ }^{24}$ Pretendeu-se aqui desenvolver apenas um argumento metodológico que aponta para um novo programa de pesquisa, o qual é consistente com certas preocupaçóes mais gerais da fronteira da teoria econômica (Mirowski, 2007). Indicou-se apenas como o modo clássico e marxiano de pensar a formação de preços pode ser reexaminado com base na matemática computacional. Construiu-se, assim, um modelo muito simples de dois mercados em que os preços de mercado flutuam, permanentemente fora do equilíbrio, em torno dos preços de produção. Apesar de suas óbvias limitações, foi possível dar sentido às seguintes palavras de Marx: "a relação entre procura e a oferta explica, portanto, por um lado, somente os desvios dos preços de mercado em relação aos valores de mercado e, por outro, a tendência à anulação desses desvios, isto é, a anulação do efeito da relação entre procura e oferta” (Marx, 1983b, p. 146).

\section{CONCLUSÕES}

O último modelo, ainda que bastante simples em face das complexidades da economia capitalista real, permite voltar à teorização de Marx sobre a formação de preços para reexaminá-la de um novo ponto de vista. Construído a partir da concepção do funcionamento do sistema econômico como metabolismo do capital, apresenta a formação de preços como processo que se desenvolve no tempo irreversível, fora do equilíbrio. Nessa perspectiva teórica, não se pode mais pensar que os preços de mercado resultam da igualdade entre demanda e oferta e que eles sintetizam a coerência possível dos mercados. Os preços de mercado passam a ser considerados como eventos momentâneos de processos homeostáticos, isto é, como ocorrências instantâneas de funcionamentos de equilibração permanentemente desequilibrados.

A perspectiva da coerência apenas se impóe - pode-se agora perceber com certa facilidade - quando as noções de demanda e de oferta são entendidas como funções analíticas, ou seja, como relações funcionais entre preços e quantidades. Dito de outro modo, a perspectiva da coerência origina-se da representação da formação de preços com base em funções agregadas, as quais são obtidas da agregação de planos exaustivos, originados de comportamentos otimizadores e plenamente informados de agentes econômicos atômicos. Quando se deixa de raciocinar sobre esse alicerce da teoria neoclássica e se passa a raciocinar com base em funções recursivas e procedimentos efetivos - ferramentas da matemática computacional e construtivista (Velupillai, 2000)

$24 \mathrm{O}$ modelo aqui apresentado, em termos de tendências da teoria econômica, caminha no mesmo sentido geral dos modelos construídos na tradição neo-schumpeteriana de Nelson e Winter (2005). Ver também, por exemplo, Possas e Dweck (2004). De qualquer modo, a questão da formação de preços tem sido ainda pouco explorada na economia computacional. Uma exceção interessante vem a ser Epstein e Axtell (1996). 
-, procura e oferta passam a explicar apenas as flutuações dos preços de mercado em torno de atratores dinâmicos. Isso exige, evidentemente, considerar a teoria do valor trabalho já que esta é a única capaz de prover os fundamentos do preço natural, do valor de mercado ou preço de produção. A alternativa vem a ser pensar a formação de preços tautologicamente, o que, aliás, tem sido feito abundantemente pelas teorias neoclássicas, de mark-up ou neo-ricardiana.

O modelo é representativo do desenrolar efetivo da economia capitalista e sua maior deficiência está em não tratar de modo explícito da formação dos próprios preços de produção. Isto, evidentemente, exigiria considerar o papel das mudanças tecnológicas e organizacionais na formação dos valores de mercado e, por esse meio, dos preços de referência. Outras complicações da economia capitalista, como a existência de meios de produção correntes e duráveis, a intermediação de setores bancários e financeiros, poderiam ser consideradas. É evidente que o modelo apresentado pode ser considerado uma porta de entrada para um amplo programa de pesquisa que investigue não só a formação de preços na economia capitalista, mas, de forma mais ampla, o próprio processo de acumulação de capital.

\section{REFERÊNCIAS BIBLIOGRÁFICAS}

Albin, P. S.; Foley, D. K. Barriers and bounds to rationality - Essays on economic complexity and dynamics in interactive systems. Princeton: Princeton University Press, 1998.

Binmore, K. Modeling rational players: Part I. In: Economics and Philosophy, n. 3, p. 179-214, 1987.

Boland, L. A. Time in economics vs. economics in time: the "Hayek problem". In: Canadian Journal of Economics, v.11, p. 240-262, 1978.

. Methodology for a new microeconomics - The critical foundations. Boston: Allen \& Unwin, 1986.

. The principles of Economics - Some lies my teachers told me. London: Routledge, 1992.

Brian Arthur, W. Out-of-equilibrium economics and agent-based modeling. In: K. Judd, K.; Tesfatsion, L. (Eds.). Handbook of computational Economics, v.2. New York: Elsevier/North Holland, 2005.

Carcanholo, R. A. Oferta e demanda e o valor em Marx. In: Revista da SEP, n. 20, 2007.

Chaitin, G. Meta Math! - The Quest for Omega. New York: Pantheon, 2005.

Epstein, J. M.; Axtell, R. L. Growing artificial societies - Social science from de bottom up. Washington: Brookings Institution Press and The MIT Press, 1996. 
Hayek, F. A. Economics and knowledge. In: Individualism and economic order. South Bend: Gageway, 1948.

Knudsen, C. Equilibrium, perfect rationality and the problem of self-reference in Economics. In: Rationality, Institutions \& Economic Methodology. U. Maki, U.; Gustafsson, B.; Knudsen, C.(Eds.) London: Routledge, 1993.

Koppl, R.; Rosser Jr, J. B. All that I have to say already crossed your mind. In: Metroeconomica, v. 53 (4), p. 339-360, 2002.

Koppl, R. Thinking impossible things: a review essay (computability, complexity and constructivity in economic analysis). In: Journal of Economic Behavior and Organization, 2007 (in press).

Leijonhufvud, A. Keynes as a marshallian. In: Cambridge Companion to Keynes. Backhouse, R.; Bateman, B. (Eds.). London: Cambridge University Press, 2006.

Lesourne, J. The economics of order and disorder - the market as organizer and creator. Oxford: Clarendon Press, 1992.

Marx, K. O Capital - Crítica da Economia Política. Livro Primeiro: O processo de produção do capital. São Paulo: Abril Cultural, 1983a; Livro Terceiro: O processo global da produção capitalista. São Paulo: Abril Cultural, 1983b.

Mirowski, P. Markets come to bits: evolution, computation and markomata in economic science. In: Journal of Economic Behavior and Organization, 2007 (in press)

Morgenstern, O. Perfect Foresight and economic equilibrium. In: Select Economic Writings of Oskar Morgenstern. Andrews Schotter. (Ed.) New York: New York University Press, 1976.

Nagel, E. The structure of science - Problems in the logic of scientific explanation. New York: Harcourt, Brace \& World, 1961.

Nelson, R. R.; Winter, S. G. Uma teoria evolucionária da mudança econômica. Campinas: Editora da Unicamp, 2005.

Possas, M. L.; Dweck, E. A multisectoral micro-macrodynamic model. In: Economia (Anpec), Selecta, v. 5(3), , p. 1-43, dez. 2004.

Prado, E. F. S. Microeconomia reducionista e microeconomia evolucionária. In: Nova Economia, 2006 (a sair).

Robinson, J. History versus equilibrium. In: Contributions to modern Economics. Oxford: Basil Blackweel, 1978.

Soromenho, J. E. C. Microfundamentos e sociabilidade. In: Economia (Anpec), n. 2, jan./jun. 2000.

Souza, J. P. A. O método de Marx e as principais interpretações para a transformação de valores em preços. (Monografia de graduação). FEA/USP, 2004. 
Velupillai, K. V. The unreasonable ineffectiveness of mathematics in Economics. Università degli Sudi di Trento - Dipartimento di Economia. Discussion Paper n. 6, 2004.

. Computable Economics. New York: Oxford University Press, 2000. 